\title{
Benign Ovarian Mucinous Tumor
}

National Cancer Institute

\section{Source}

National Cancer Institute. Benign Ovarian Mucinous Tumor. NCI Thesaurus. Code C40039.

A non-metastasizing neoplasm that arises from the ovary and is characterized by the presence of neoplastic epithelium that resembles the epithelium of the endocervix or gastrointestinal tract. It includes mucinous adenofibroma, mucinous cystadenofibroma, and mucinous cystadenoma. 